\title{
Skull Base Penetration Due to Cervical Impalement Injury: A Case Report and Review of the Literature
}

\author{
Kei Miyata ${ }^{1,2 *}$, Takeshi Mikami ${ }^{1}$, Yukinori Akiyama ${ }^{1}$, Toshiya Sugino ${ }^{1}$, Reiko Kiyan ${ }^{2}$, \\ Eichi Narimatsu' ${ }^{2}$, Nobuhiro Mikuni ${ }^{1}$ \\ ${ }^{1}$ Department of Neurosurgery, Sapporo Medical University, Sapporo, Japan \\ ${ }^{2}$ Department of Emergency Medicine, Sapporo Medical University, Sapporo, Japan \\ Email: ${ }^{*}$ miyata@sapmed.ac.jp
}

Received October 25, 2013; revised November 25, 2013; accepted December 3, 2013

Copyright (C) 2014 Kei Miyata et al. This is an open access article distributed under the Creative Commons Attribution License, which permits unrestricted use, distribution, and reproduction in any medium, provided the original work is properly cited. In accordance of the Creative Commons Attribution License all Copyrights @ 2014 are reserved for SCIRP and the owner of the intellectual property Kei Miyata et al. All Copyright (C) 2014 are guarded by law and by SCIRP as a guardian.

\begin{abstract}
Impalement injury is a rare type of trauma, and the management should be performed carefully. In cases with impalement injuries, the area of injury and crush might be extensive because the penetrating object itself is generally large and long. Herein, we report our experience with a rare case of cervical impalement injury caused by an iron reinforcing bar penetrating the optic canal and thereby causing brain contusion. A 32-year-old man fell while working at a construction site and sustained an injury due to an iron reinforcing bar that penetrated his right neck. On arrival at the hospital, consciousness was clear and the bar was removed by himself. The patient had lost the sight in his right eye, and cerebrospinal fluid (CSF) rhinorrhea was present. Based on the results of computed tomography (CT) of the head and neck, the bar was thought to have passed through the right mandible and the right optic canal and penetrated the frontal lobe. Surgical repair of frontal base was performed using femoral fascia, completely stopping the CSF leak. The patient was discharged on the 31st hospital day walking independently. In our present case, the top of a foreign body was reached an intracranial site. Impalement injuries require detailed assessment of the injury sites because outcomes depend on the severity of injuries at surrounding anatomical structures. Multiple planar reconstruction using recent multidetector row $C T$ scanning was considered to be useful for the assessment of penetrating routes and injury severity.
\end{abstract}

\section{KEYWORDS}

Impalement Injury; Penetrating Injury; Skull Base; Multiple Planar Reconstruction

\section{Introduction}

Among penetrating injuries, those caused by a relatively blunt object are called impalement injuries. Impalement injuries are sustained by falling onto bar-like objects such as stakes and iron rods or by being stuck by projectiles from an explosion. The penetrating objects are generally larger than knives, and the area of injury and crush is extensive. Moreover, the penetrating objects are frequently contaminated. Impalement injury is a relatively rare type of trauma, and commonly accompanied by injuries involving the bladder or rectum. There are a few reports on head and neck impalement injuries, and in which the penetrating routes to intracranial regions were

\footnotetext{
*Corresponding author.
}

discussed [1,2]. Of these, few cases are reported previously on cervical impalement injuries that penetrated the skull base to reach the intracranial region $[3,4]$. Herein, we report a rare case of cervical impalement injury caused by an iron reinforcing bar that penetrated the optic canal to reach the frontal lobe. The literature on head and neck impalement injuries is also reviewed.

\section{Case Report}

A 32-year-old previously healthy man slipped and fell while working at a construction site, and sustained an impalement injury due to an iron reinforcing bar $13 \mathrm{~mm}$ in diameter protruding upward about $70 \mathrm{~cm}$ from the concrete foundation that penetrated his right neck at a 
point approximately $3 \mathrm{~cm}$ below the right angle of the mandible (Figures 1(a)-(b)). The penetrated bar was extracted by himself. Two and half hours after the injury, the patient was arrived at the emergency room of our hospital. On arrival, the Glasgow Coma Scale was 15 (E4, V5, M6), the visual acuity in his right eye had been completely lost, but there were no other neurological abnormalities. The pupil was $4 \mathrm{~mm}$ in the right eye and $3 \mathrm{~mm}$ in the left eye. The direct light reflex was absent in the right eye, and the indirect light reflex was absent in the left eye. The injury was present in the right neck at a point approximately $3 \mathrm{~cm}$ below the angle of the mandible (Figure 1(c)). Epistaxis and cerebrospinal fluid (CSF) rhinorrhea was recognized. Transnasal fiberscope examination revealed the swelling at the posterior wall of the nasopharynx, but the point of penetration in the pharyngeal wall could not be found. Computed tomography (CT) of the neck showed emphysema along the carotid artery to the level of the cricoid cartilage. It also revealed that emphysema continued from the neck to the frontal lobe through the sphenoid sinus (Figures 2(a)-(b)). CT of the head showed mixed densities in the right frontal lobe considered to be bone fragments and contusional brain (Figure 2(c)). Based on these findings, the reinforcing bar appeared to have penetrated the neck below the right mandible, the right posterior ethmoid and sphenoid sinuses, the right optic canal, and the frontal base

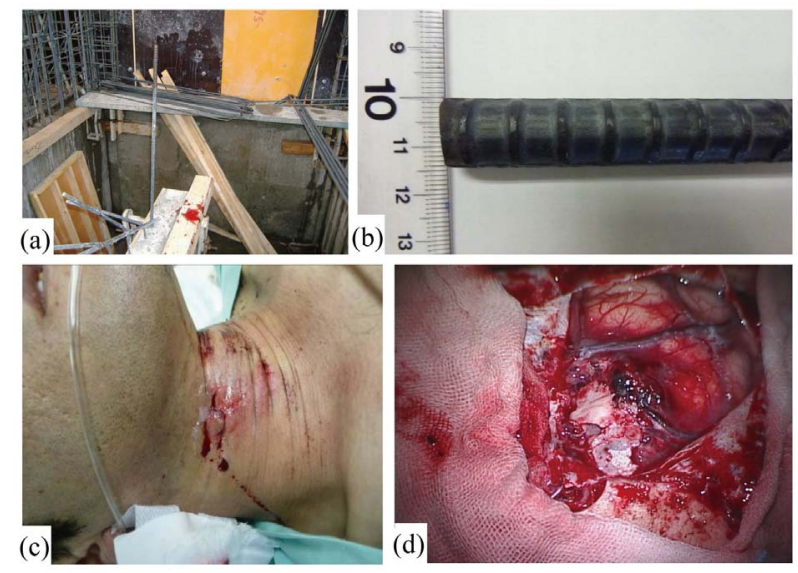

Figure 1. The patient who sustained a penetrating injury to zone 2 of the neck. The patient was admitted in the emergency room after the removal of the foreign body on his own. (a) Photograph showing iron reinforcing bar protruding upward from the concrete foundation about $70 \mathrm{~cm}$ at the scene of the accident. The patient stumbled while working at construction sites; (b) Photograph showing an reinforcing bar $13 \mathrm{~mm}$ in diameter the same type as the foreign body penetrating from the neck into the brain; (c) Photograph on admission showing a small lacerated wound in the right neck; (d) Intraoperative photograph revealed the injured cortical vein and brain contusion. Few bone fragments which seemed to be the frontal cranial base were observed on the surface of the contusion brain.

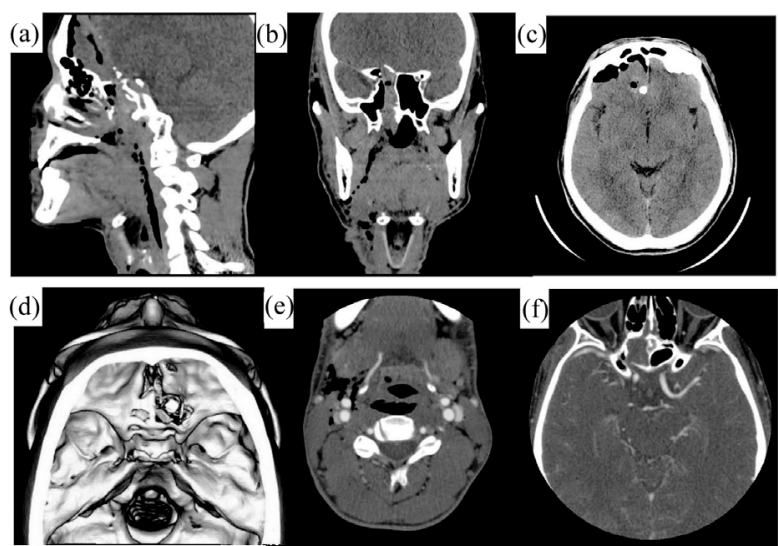

Figure 2. Plain CT scan (sagittal view (a) and coronal view (b)) of the head and neck. The reinforcing bar appeared to penetrate the neck and pass through the soft tissue in the nasopharynx and destroy the sphenoid sinus and right optic canal to reach the frontal convexity in association with penetrating brain injury. Plain head CT scan showing pneumocephalus (c), a small intracerebral hematoma and bone fragment associated with air bubbles in the right frontal lobe. 3D-CT scan (d) shows the destruction of the frontal cranial base by the iron bar. Enhanced CT (e) showed no definitely damaged vessels or extra-vascular leakage of contrast medium.

(Figure 2(d)). The bar entered from the neck was penetrated approximately $20 \mathrm{~cm}$ from the entry site. Threedimensional (3D)-CT angiography and cerebral angiography showed no extra-vascular leakage of contrast medium (Figures 2(e)-(f)).

After admission, a continuous CSF rhinorrhea had not been improved. On the 3rd hospital day, surgical repair of the frontal base was performed. After bifrontal craniotomy, the damage of the dura mater and the brain parenchyma at the right frontal base was identified. An injured cortical vein, hematoma, and a few bone fragments was recognized around the surface of the brain (Figure 1(d)). Removal of hematoma and debridement of the contusional brain were performed. The femoral fascia was used for duraplasty, and the paranasal sinus was covered with a periosteal flap, and then cranioplasty was performed. Ceftriaxone sodium was administered, starting on the day of admission, for 11 days. Postoperatively, no neurological abnormalities had been developed except unilateral visual loss and mild neuropsychological deficit. On the 31st hospital day, he was discharged walking independently and has been doing well without recurrence of CSF rhinorrhea or the occurrence of infectious complications.

\section{Discussion}

\subsection{Head and Neck Impalement Injuries}

In total, 31 patients including our case with head and neck impalement injuries were previously reported, and 
that were reviewed [1-25]. There were 26 men and 5 women, and the mean age was 36.4 years. The most frequently reported causative event was a fall, in 17 patients, followed by accidental impacts in 7 , traffic accidents in 4 , and violence in 3 . The impaling objects were metallic in 25 patients and wooden in 6 . Thus, although the head and neck impalement injury is rare, most of the cases are male of adolescence of the workman's accident, and social influence is large. The most frequently reported route was trans-orbital, in 12 patients, followed by trans-facial in 9, trans-cervical in 8 , and trans-oral in 2 . The 8 cases of trans-cervical route including our case were summarized in Table 1. Of these, the directions of impalement were divided into two groups: cranial course (the impaling objects entered cranially, including cases with impalement of the orbit and paranasal sinuses; $n=5$ ) and pharynx/ oral cavity course (the objects stopped within the pharynx or oral cavity; $n=4)$. All of the impaling objects entering via the trans-cervical cranial course were extracted by the patient himself/herself before visiting a hospital. Major arterial injuries occurring along the route of penetration critically impact the prognosis of impalement injury patients. In the present review of patients with impalement injuries, none died as a direct consequence of cervical arterial injuries in the neck or extracranial regions through which the object had passed. Survival was dependent on the presence or absence of intracranial injuries (vascular injuries in the brain stem and intracranial regions) by a foreign body at any of the points of penetration. When the top of a foreign body penetrated the pharynx or oral cavity, the clinical problem was an airway emergency due to the foreign body itself, bleeding, or edema [1,6,9,10,23].

\subsection{Penetrating Neck Injuries}

From the viewpoint of penetrating neck injuries, all the penetrating neck injuries are classified according to injury location into three zones [26]. Zone I (lower part) is from the cricoid cartilage to the suprasternal notch and the clavicle, containing large vessels in the thoracic outlet, vertebrae, vertebral artery, lung, trachea, esophagus, spinal cord, and thoracic duct. Zone II is the widest, from the angle of the mandible to the rostral of the corticoid cartilage, including the jugular vein, vertebral and common carotid arteries, inner and outer branches of the carotid artery, trachea, esophagus, larynx, and spinal cord. The injury of our patient was classified into zone II. Zone III is above the angle of the mandible to the cranial base, containing the jugular vein, vertebral artery, the distal part of the internal carotid artery, and the pharynx. Treatments, managements, and prognoses are zone-dependent. Vascular injuries in the mediastinum may occur in zone I, resulting in difficulty controlling bleeding, and zone I injuries have the highest mortality rate. For zone III injuries, an operative treatment may be indicated because these injuries affect the cervical artery or lower cranial nerves. Moreover, penetrating neck injuries are characterized by combined risks including those for laryngotracheal, vascular, pharynx, and cranial nerve injuries. The overall mortality is assumed to be $3 \%$ to $10 \%$ [27]. Patients with unstable airway, respiratory and circulatory dynamics, widespread subcutaneous emphysema, pulsatile bleeding, or deterioration of neurological findings are considered to be in an unstable state, and emergent surgical intervention should be taken into consideration [28]. Severity of injury is difficult to determine based on the superficial appearance of the injury. Entire routes and

Table 1. Summary of patients with neck impalement injury by blunt weapon.

\begin{tabular}{|c|c|c|c|c|c|c|c|c|c|c|c|}
\hline Year & Authors & Age/Sex & Cause & Weapon & $\begin{array}{c}\text { Self } \\
\text { Removal }\end{array}$ & Route & $\begin{array}{c}\text { Consciousness } \\
\text { Impairment }\end{array}$ & $\begin{array}{c}\text { Brain } \\
\text { Contusion }\end{array}$ & Site & Neurological Deficit \&ADL & Outcome \\
\hline 1999 & Nakai K & $61 / \mathrm{M}$ & Fall & $\begin{array}{l}\text { Iron Reinforcing } \\
\text { Bar }\end{array}$ & + & A, C, D & GCS14 & + & FL & - & Alive \\
\hline 2001 & Wada T & $15 / \mathrm{M}$ & Fall & $\begin{array}{l}\text { Iron Reinforcing } \\
\text { Bar }\end{array}$ & + & A, C, D & Somnolent & + & FL & - & Alive \\
\hline 2002 & Hoshi J & $55 / M$ & Fall & $\begin{array}{l}\text { Iron Reinforcing } \\
\text { Bar }\end{array}$ & - & A, B, C & & - & & Bilateral Blind & Alive \\
\hline 2007 & Aoyagi Y & $85 / M$ & Fall & Iron Pole & - & A & & - & & - & Alive \\
\hline 2009 & $\begin{array}{l}\text { Mansour } \\
\text { AM }\end{array}$ & $51 / \mathrm{M}$ & Fall & $\begin{array}{l}\text { Iron Reinforcing } \\
\text { Bar }\end{array}$ & - & B, C, A & & - & & - & Alive \\
\hline 2010 & Satou H & $51 / \mathrm{M}$ & Fall & Chip Wood & - & A & & - & & - & Alive \\
\hline 2011 & $\begin{array}{l}\text { Perdekamp } \\
\quad \text { MG }\end{array}$ & $78 / \mathrm{F}$ & Fall & Bamboo & + & A, D & GCS12 & + & TL & Hemiparesis & Dead \\
\hline 2013 & present case & $32 / \mathrm{M}$ & Fall & $\begin{array}{l}\text { Iron Reinforcing } \\
\text { Bar }\end{array}$ & + & A, C, D & GCS15 & + & FL & $\begin{array}{l}\text { Unilateral Visual Loss, Mild } \\
\text { Neuropsychological Deficit }\end{array}$ & Alive \\
\hline
\end{tabular}

Route: A; neck/pharynx, larynx, B; orbit, C; paranasal sinus, D; brain parenchymal; Consciousness Impairment: GCS; Glasgow Coma Scale, Site of brain contusion: FL; frontal lobe, TL; temporal lobe. 
areas including the entry point based on the type and penetrating angle of an impaling object should be taken into consideration for assessment. CT and 3D-CT angiography are useful in screening patients for tracheopharyngeal or vascular injuries [5,6,29-32]. Especially, 3DCT using the multiple planar reconstruction (MPR) method can produce an image from an arbitrary angle along the impaling route. Therapeutic protocols for head and neck impalement injuries have been developed incorporating these imaging modalities [33-37]. In these protocols, angiography or contrast-enhanced CT could not be performed for preoperative assessment because the foreign body interfered with scanning. In these patients, the presence or absence of vascular injury and tracheoesophageal injury should be identified directly during endoscopic examinations or operations.

\subsection{Skull Base Penetration of Impalement Injury}

The features of skull base penetration of impalement injury are as follows: there is a blunt injury aspect accompanying contusion of the brain parenchyma due to the blunt top of the object; major vessels, which are relatively flexible and elastic, are seldom injured when an object penetrates at low speed. Even if major vessels are injured, it might not result in fetal bleeding providing a tamponade effect so long as the foreign body is not removed $[1,6,10]$. However, when the object reaches the brain stem or cerebellum in the posterior fossa or injures the venous sinus, removal of the penetrating object may be lifethreatening [2,18,21]. Even in cases with supratentorial lesions, assessment of vascular injury before treatment is essential because there may be an accompanying pseudoaneurysm, intraventricular hematoma, or subarachnoid hemorrhage $[3,38]$. Particularly, since the orbital hiatus (posterior wall type) is anatomically located adjacent to the cranial nerves, internal carotid artery, pituitary gland, and cavernous sinus, a fatal vascular injury, brain stem injury, or cranial nerve palsy may develop due to the impaling foreign body $[8,17,23]$.

There is no definite evidence with respect to surgical treatment for penetrating injuries. The retention of intracranial foreign bodies and contaminated bone fragments, CSF leaks, air sinus injuries, and trans-ventricular injuries may create a risk for late-onset infectious complications [39]. Therefore, hemostasis, debridement, and duraplastyare sometimes needed for preventing secondary complications including meningitis and brain abscess [40]. In the present case, because the size of the defect in the frontal skull base was wide and the CSF leak was continued to be unlikely to resolve spontaneously with conservative therapy, a radical operation was performed. It is noteworthy that intracranial infections often develop during the chronic phase, so as to long-term follow-up should be necessary [41,42].

\section{Conclusion}

We report our experience managing a case with a cervical impalement injury penetrating skull base due to an iron reinforcing bar. Although the cervical impalement injury is rare, most of the cases which reviewed are male of adolescence of the workman's accident. Survival is dependent on the presence or absence of major intracranial vascular injuries, brain stem injuries, and airway emergencies. Therefore, 3D-CT using the MPR was useful for detecting the penetrating route of the object and establishing the evaluation of surrounding anatomical structure.

\section{REFERENCES}

[1] H. Sato, K. Shiga, T. Oshima and T. Kobayashi, “Cervical Impalement Injury Penetrated to Hypopharynx through the Carotid Bifurcation: A Case Report," Journal of Japan Society for Head and Neck Surgery, Vol. 20, No. 2, 2010, pp. 135-139.

[2] Q. Wang, T. Michiue and H. Maeda, "Fatal Facial-Intracranial Impalement Injury in an Accidental Fall from a Height: An Autopsy Cse Report with a Review of the Literature," Forensic Science International, Vol. 200, No. 1-3, 2010, pp. 21-24. http://dx.doi.org/10.1016/j.forsciint.2010.04.010

[3] H. Nakai, Y. Tamura, T. Tanaka, A. Hodozuka, K. Hashizume, T. Tosho, R. Matsui and H. Iwakiri, “A Case of a Traumatic Anterior Cerebral Artery Aneurysm Following the Penetration of the Skull Base by an Iron Rod," No Shinkei Geka, Vol. 27, No. 6, 1999, pp. 583-589.

[4] T. Wada, M. Nakajima and T. Abe, "Transcerviconasopharyngeal Penetrating Brain Injury by an Iron Rod," JJAAM, Vol. 12, 2001, pp. 755-759.

[5] K. Al-Sebeih, K. Karagiozov and A. Jafar, "Penetrating Craniofacial Injury in a Pediatric Patient," Journal of Craniofacial Surgery, Vol. 13, No. 2, 2002, pp. 303-307. http://dx.doi.org/10.1097/00001665-200203000-00022

[6] Y. Aoyagi, T. Tobita, K. Tabuchi and A. Hara, "A Case of Impalement Injury,” Practica Oto Rhino-Laryngologica, Vol. 100, No. 9, 2007, pp. 765-768.

[7] K. Arashiro and N. Fujii, "Unusual Facial Impalement Injury,” Plastic and Reconstructive Surgery, Vol. 108, No. 1, 2001, pp. 145-147. http://dx.doi.org/10.1097/00006534-200107000-00021

[8] C. Balasubramanian, C. K. Jadun and P. S. Dias, “Transorbital Intracranial Penetrating Injury-An Anatomical Classification," Surgical Neurology, Vol. 71, No. 2, 2009, pp. 238-240. http://dx.doi.org/10.1016/j.surneu.2007.07.050

[9] K. O. Boahene, D. L. Schulte and A. E. Brissett, "Craniofacial Metal Bolt Injury: An Unusual Mechanism,” Journal of Trauma, Vol. 56, No. 3, 2004, pp. 716-719. http://dx.doi.org/10.1097/01.TA.0000038551.42592.C2

[10] J. Hoshi and M. Suzuki, "Impalement Injury through the Chest to Forehead,” Practica Oto Rhino-Laryngologica, 
Vol. 95, No. 10, 2002, pp. 1083-1086.

[11] S. Kasamo, K. Kusumoto, M. Nakayama, K. Kadota, M. Atsuchi and Y. Yamamoto, "Transorbital Penetrating Brain Injury,” No Shinkei Geka, Vol. 20, No. 4, 1992, pp. 433438.

[12] S. W. Kim, J. T. Kim, S. H. Cho, Y. H. Kim and K. T. Hwang, "Management of an Unusual Craniofacial Impalement Injury by a Metallic Foreign Body,” Journal of Craniofacial Surgery, Vol. 23, No. 2, 2012, pp. e140-e146. http://dx.doi.org/10.1097/SCS.0b013e31824cdc2b

[13] A. Lauterbach and P. Betz, "Fatal Impalement Injury of the Head Due to a Curtain Rail," International Journal of Legal Medicine, Vol. 120, No. 6, 2006, pp. 380-382. http://dx.doi.org/10.1007/s00414-006-0097-7

[14] G. Long, B. Storm and J. Graham, "Cranial Impalement in a Child Driving an All-Terrain Vehicle," Pediatric Emergency Care, Vol. 27, No. 5, 2011, pp. 409-410. http://dx.doi.org/10.1097/PEC.0b013e31821d86ea

[15] A. M. Mansour, S. Haddad, G. Mollayess, "Visual Recovery after Impalement Injury of the Orbit by Reinforced Steel Bar,” BMJ Case Rep, 2009.

[16] J. Maruya, M. Wakai and U. Kaneko, "Brain Abscess Following Transorbital Penetrating Injury Due to Bamboo Fragments-Case Report," Neurologia Medico-Chirurgica (Tokyo), Vol. 42, No. 3, 2002, pp. 143-146. http://dx.doi.org/10.2176/nmc.42.143

[17] S. Nakao, M. Ueno, A. Yamamoto, Y. Mizushima, K. Ishikawa and T. Matsuoka, "Pituitary Injury and Progressive Pseudoaneurysm of the Internal Carotid Artery Following Transorbital Penetrating Injury,” JJAAM, Vol. 20, 2009, pp. 887-894.

[18] N. Nathoo, S. S. Nadvi, S. R. Naidoo and E. Gouws, "Transcranial Brainstem Stab Injuries: A Retrospective Analysis of 17 Patients,” Neurosurgery, Vol. 47, No. 5, 2000, pp. 1117-1122. http://dx.doi.org/10.1097/00006123-200011000-00018

[19] T. Okunaga, T. Yoshioka, T. Shimizu, H. Yamashita and H. Yokoyama, "A Case of Transorbital Penetrating Brain Injury by a Blunt Metal Rod,” No Shinkei Geka, Vol. 38, No. 3, 2010, pp. 293-298.

[20] J. M. Pascual and R. Carrasco, "Penetrating Ballistic-Like Frontal Brain Injury Caused by a Metallic Rod,” Acta Neurochir (Wien), Vol. 151, No. 6, 2009, pp. 689-691. http://dx.doi.org/10.1007/s00701-009-0222-8

[21] A. K. Petridis, H. Barth, U. O. Wiesbrock, A. I. Gutmann and H. M. Mehdorn, "Transorbital Impalement Injury with Massive Intracranial Lesion Not Detected by Cranial CT Scan,” Clinical Neuroradiology, Vol. 21, No. 3, 2011, pp. 167-170. http://dx.doi.org/10.1007/s00062-010-0051-4

[22] M. G. Perdekamp, S. Pollak and A. Thierauf, "Intracranial Impalement with Entrance Site in the Mandibular Region: Postmortem Elucidation of an Accidental Fall on a Wooden Plant Stick,” Forensic Science International, Vol. 209, No. 1-3, 2011, pp. e35-e40.

http://dx.doi.org/10.1016/j.forsciint.2011.03.034

[23] M. Schreckinger, B. G. Thompson, F. La Marca and O. Sagher, "Transorbital Penetrating Injury: Case Series, Re- view of the Literature, and Proposed Management Algorithm,” Journal of Neurosurgery, Vol. 114, No. 1, 2011, pp. 53-61. http://dx.doi.org/10.3171/2010.8.JNS10301

[24] S. Shetty, S. Gupta, Balasubramanya, S. Hasan, M. Cherian and Srikrishna, "Facio-Cervical Transfixion by a Metallic Rod: A Case Report,” American Journal of Otolaryngology, Vol. 22, No. 2, 2001, pp. 160-163. http://dx.doi.org/10.1053/ajot.2001.22589

[25] S. Tanaka, Y. Hirashima and S. Endo, "A Case of a Enetrating Head Injury by an Iron Rod," Journal of Japanese Congress on Neurological Emergencies, Vol. 18, 2005, pp. 48-51.

[26] A. J. Roon, "Evaluation and Treatment of Penetrating Cervical Injuries," Journal of Trauma, Vol. 19, No. 6, 1979, pp. 391-397.

http://dx.doi.org/10.1097/00005373-197906000-00001

[27] R. B. Bell, E. J. Dierks, B. E. Potter and W. B. Long, “Management of Penetrating Neck Injuries: A New Paradigm for Civilian Trauma,” Journal of Oral Maxillofac Surgery, Vol. 65, No. 4, 2008, pp. 691-705. http://dx.doi.org/10.1016/j.joms.2006.04.044

[28] S. A. Tisherman, F. Bokhari, B. Collier, J. Cumming, J. Ebert, M. Holevar, et al., "Clinical Practice Guideline: Penetrating Zone II Neck Trauma,” Journal of Trauma, Vol. 64, No. 5, 2008, pp. 1392-1405. http://dx.doi.org/10.1097/TA.0b013e3181692116

[29] S. H. Cho and C. W. Park, "CT Angiography with 3D Reconstruction for the Initial Evaluation of Penetrating Neck Injury with Retained Knife,” Otolaryngol Head Neck Surgery, Vol. 36, No. 3, 2007, pp. 504-505. http://dx.doi.org/10.1016/j.otohns.2006.08.015

[30] S. Francis, N. Rogers and S. C. Stain, "Diagnosis and Management of Laryngotracheal Trauma," Journal of the National Medical Association, Vol. 94, No. 1, 2002, pp. 21-24.

[31] K. Inaba, F. Munera, M. McKenney, L. Rivas, M. de Moya, H. Bahouth, et al., "Prospective Evaluation of Screening Multislice Helical Computed Tomographic Angiography in the Initial Evaluation of Penetrating Neck Injuries," Journal of Trauma, Vol. 61, No. 1, 2006, pp. 144-149. http://dx.doi.org/10.1097/01.ta.0000222711.01410.bc

[32] M. Vaiman and M. Puterman, “3D Computer-Assisted Assessment of Complicated Penetrating Foreign Bodies Cases in ENT Practice," European Archives of OtoRhino-Laryngology, Vol. 266, No. 10, 2009, pp. 1599-1603. http://dx.doi.org/10.1007/s00405-008-0894-3

[33] R. E. Azuaje, L. E. Jacobson, J. Glover, G. A. Gomez, G. H. Rodman Jr., T. A. Broadie, et al., "Reliability of Physical Examination as a Predictor of Vascular Injury after Penetrating Neck Trauma," The American Journal of Surgery, Vol. 69, No. 9, 2003, pp. 804-807.

[34] G. M. Buchalter, M. V. Reichman and J. Jacobs, "Penetrating Trauma to the Head and Neck from a Nail Gun: A Unique Mechanism of Injury,” Ear, Nose Throat Journal, Vol. 81, No. 11, 2002, pp. 779-783.

[35] G. S. Gussack, "Penetrating Facial Trauma: A Management Plan,” South Medical Journal, Vol. 81, No. 3, 1988, pp. 297-302. http://dx.doi.org/10.1097/00007611-198803000-00003 
[36] F. Múnera and L. A. Rivas, "Penetrating Injury of the Neck: Use of Helical Computed Tomographic Angiography," Journal of Trauma, Vol. 58, No. 2, 2005, pp. 413-418. http://dx.doi.org/10.1097/01.TA.0000141892.07192.55

[37] I. Okada, J. Sasaki and H. Yoshii, "Is Our Selective Management Protocol for Zone 2 Neck Stab Wound Effective?” Journal of Japan Association of Surgery Trauma, Vol. 19, No. 4, 2005, pp. 323-328.

[38] B. A. Pruitt Jr., "Vascular Complications of Penetrating Brain Injury,” Journal of Trauma, Vol. 51, No. 2S, 2001, pp. S26-S28.

http://dx.doi.org/10.1097/00005373-200108001-00007

[39] B. A. Pruitt Jr., "Management of Cerebrospinal Fluid Leaks,"
Journal of Trauma, Vol. 51, No. 2S, 2001, pp. S29-S33. http://dx.doi.org/10.1097/00005373-200108001-00008

[40] B. A. Pruitt Jr., "Surgical Management of Penetrating Brain Injury,” Journal of Trauma, Vol. 51, No. 2S, 2001, pp. S16-S25.

http://dx.doi.org/10.1097/00005373-200108001-00006

[41] B. A. Pruitt Jr., "Antibiotic Prophylaxis for Penetrating Brain Injury,” Journal of Trauma, Vol. 51, No. 2S, 2001, pp. S34-S40. http://dx.doi.org/10.1097/00005373-200108001-00009

[42] C. F. Miller and B. J. Colombi, "The Danger of Intracranial Wood,” Surgical Neurology, Vol. 7, No. 2, 1977, pp. 95-103. 